\title{
RAIL INTEGRITY EXPERIENCE ON THE WASHINGTON METRO SYSTEM
}

\author{
Benjamin Frison \\ Washington Metropolitan Area Transit Authority \\ Office of Infrastructure Services \\ Washington, DC, USA
}

\section{ABSTRACT}

The Washington Metropolitan Area Transit Authority (WMATA) provides passenger rail service to the nation's capital. Although the rail system carries only passenger trains, the rail integrity issues that WMATA must manage are similar to those that freight railroads also face. These issues include occurrences of broken rail from internal rail head defects, detection of such defects, and repair of the rail to restore service. Another example is the development of damage on the running surface of the rail, called rolling contact fatigue (RCF). Such surface damage is known to adversely affect the detection of internal rail head defects beneath RCF conditions. While WMATA's rail integrity issues may be similar to those that freight railroads also encounter, the management of such issues are different, which are also discussed in this paper.

This paper describes the recent experience of broken rails on the WMATA rail system. In addition, results from engineering fracture mechanics analyses are presented to help understand how operational, environmental, design, and maintenance factors influence rail failure.

\section{INTRODUCTION}

The Washington Metropolitan Area Transit Authority (WMATA) provides service to a population of 5 million within a 1,500 square-mile jurisdiction. The transit zone consists of the District of Columbia, the suburban Maryland counties of Montgomery and Prince George's and the Northern Virginia counties of Arlington, Fairfax, and Loudoun and the cities of Alexandria, Fairfax, and Falls Church. Figure 1 shows a map of the WMATA rail system, which consists of six "color" lines: Blue, Green, Orange, Red, Silver, and Yellow. Today WMATA serves 91 stations and has 118 miles of track [1].

\author{
David Y. Jeong \\ Volpe National Transportation Systems Center \\ US Department of Transportation \\ Cambridge, Massachusetts, USA
}

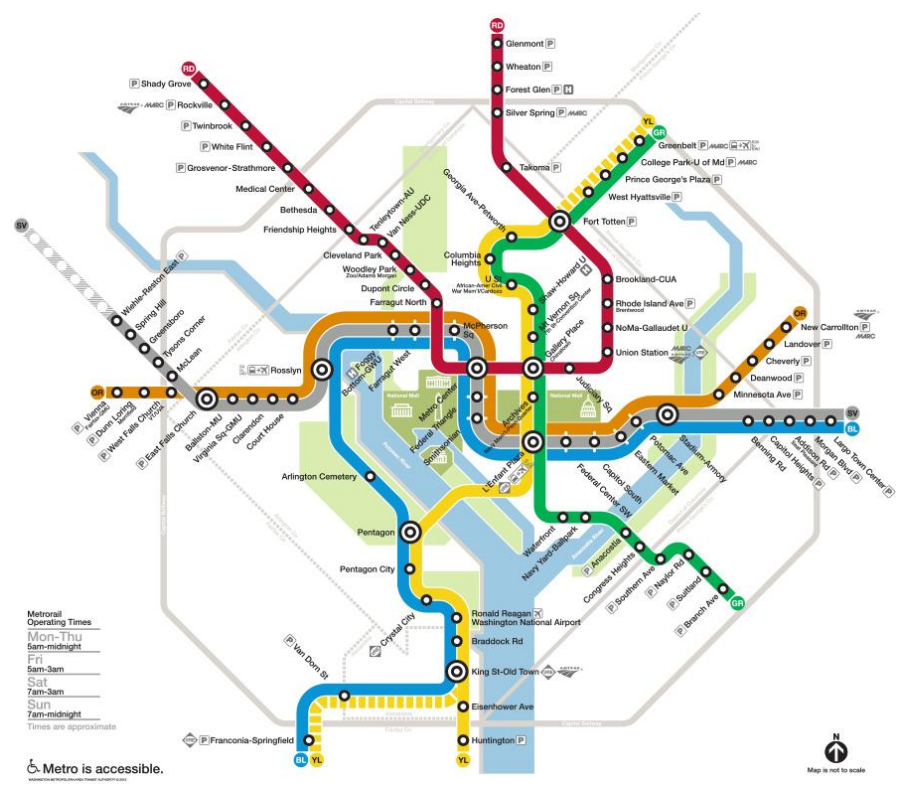

Figure 1: WMATA Rail System Map

Although the Metro rail system is a passenger-service railroad, WMATA must deal with rail integrity issues that are similar to those that freight railroads typically encounter. This paper describes the rail defects that are common to WMATA and typical freight experience. Strategies to manage or control rail integrity are also discussed in the context of similarities and differences between transit and freight railroad systems. In addition, results from engineering analyses are presented to help provide insight into the occurrence of rail failures. 


\section{WMATA DESIGN CHARACTERISTICS}

The rail section used on the Metro rail system is headhardened $115 \mathrm{RE}$ (see Figure 2). By comparison, freight railroads typically use heavier rail sections (such as $132 \mathrm{RE}$, $136 \mathrm{RE}$, or $141 \mathrm{RE}$ ) to compensate for the higher wheel loads associated with freight traffic. Based on the section properties listed in Table 1, rail bending stress is reduced by about 24 percent in the base and by 29 percent in the head when $141 \mathrm{RE}$ is used to replace $115 \mathrm{RE}$ under the same wheel load.

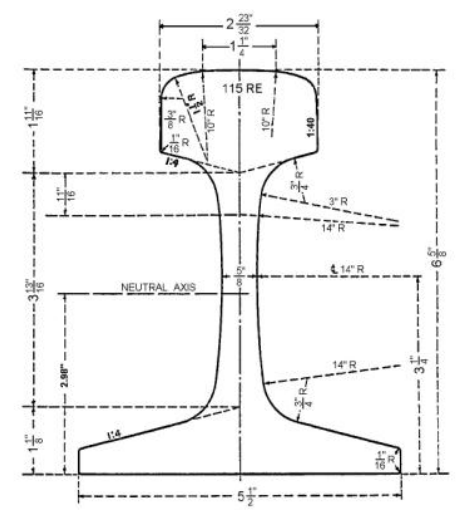

Figure 2: 115 RE Rail

Table 1: Section Properties for 115 RE and 141 RE Rail

\begin{tabular}{|l|c|c|}
\hline & $115 \mathrm{RE}$ & $141 \mathrm{RE}$ \\
\hline Cross Sectional Area $\left(\mathrm{in}^{2}\right)$ & 11.25 & 13.8 \\
\hline Moment of Inertia, $I_{x x}\left(\mathrm{in}^{4}\right)$ & 65.85 & 100.7 \\
\hline Moment of Inertia, $I_{v y}\left(\mathrm{in}^{4}\right)$ & 10.74 & 14.9 \\
\hline Height of Neutral Axis (inches) & 2.98 & 3.48 \\
\hline
\end{tabular}

Several factors influence the service life of rail. In this context, rail life means the number of wheel passages or the equivalent gross weight of trains rolling over the rail. These factors include: chemical composition of the rail steel, train operating speeds, tonnage, tie-ballast support conditions, and track maintenance programs. Chemical composition affects the microstructure and the mechanical properties of rail steel. Table 2 lists the minimum requirements for rail steel used on the Metro rail system in terms of yield strength and ultimate tensile strength. Modern rail refers to heat-treated, head-hardened rail.

Table 2: Minimum Requirements for WMATA Rail

\begin{tabular}{|l|c|c|}
\hline & Modern & Older Rail \\
\hline Yield Strength (ksi) & 120 & 75 \\
\hline Ultimate Tensile Strength (ksi) & 170 & 135 \\
\hline
\end{tabular}

Other design characteristics of the WMATA rail system are listed follows:

- The track gauge, or distance between the inner faces of the rails, is $561 / 4$ inches on tangent track and opens out to $561 / 2$ inches on curves.

- Although the Metro rail system was designed for automatic train control operation, WMATA has been operating in manual mode since 2009 .

- Historically, the target for the rail neutral (i.e. stress-free) temperature for outdoor ballasted track is $85^{\circ} \mathrm{F}$. Currently, the target is $95^{\circ} \mathrm{F}$.

- Many curves have been over-designed with excessive superelevation.

- The passenger cars on WMATA have 1:20 tapered wheels with a $70^{\circ}$ flange angle, which was changed from $63^{\circ}$.

\section{RAIL DEFECTS}

Cracks or defects can develop and grow internally in the rail from the repetition of wheel loads rolling over the rail, or metal fatigue. One of the most common rail defects caused by metal fatigue is called the detail fracture, which originates in the upper gage corner of the rail head near the running surface. Figure 3 is an exemplar photograph of a detail fracture [2].

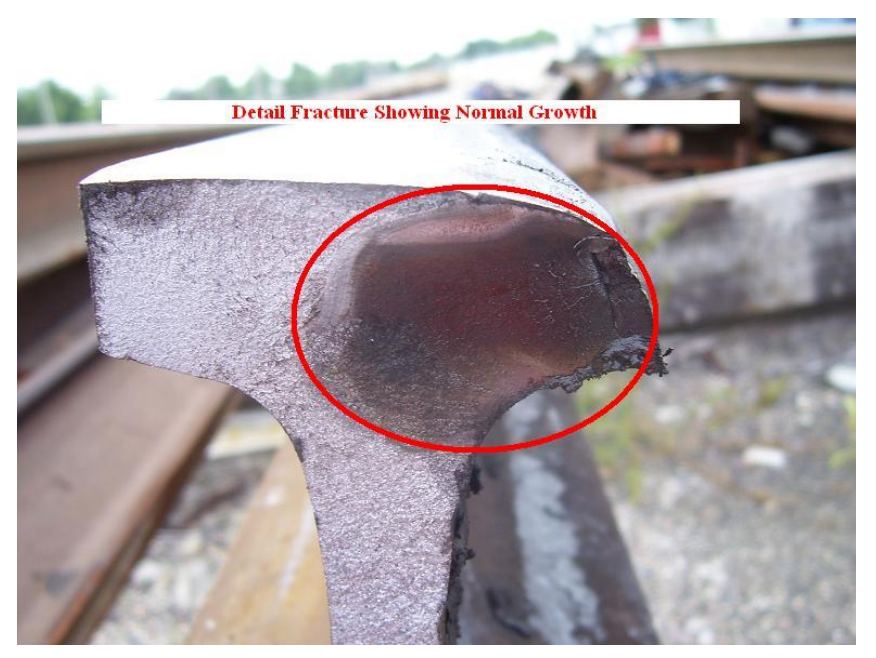

Figure 3: Photograph of Detail Fracture in Rail [2]

Figure 4 is a photograph of a broken rail that occurred between the Braddock Road and Washington National Airport Stations on March 27, 2014. The low temperature for this particular day was $15^{\circ} \mathrm{F}$ according to climatological data from the National Weather Service for the Sterling-Dulles area [3]. The rail contains a detail fracture in the head, and batter on the running surface. 


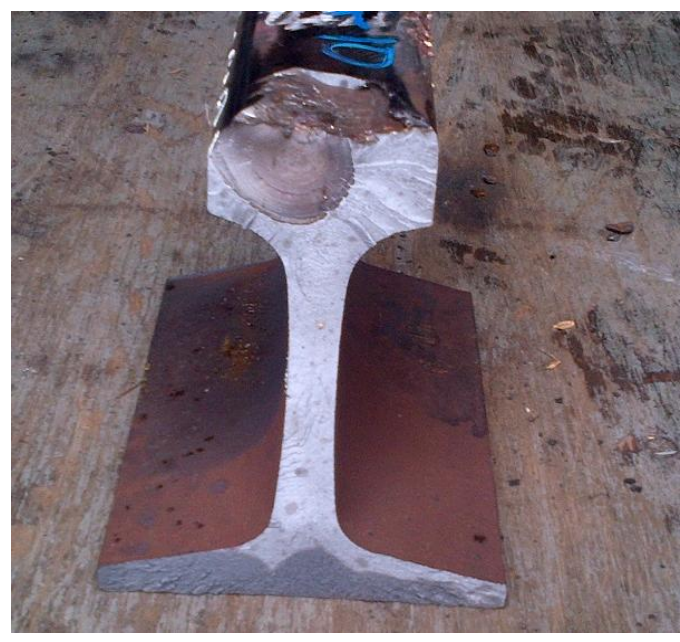

\section{Figure 4: Photograph of Broken Rail Found Near Braddock Road}

Other types of defects that develop and propagate internally in the rail head from metal fatigue are vertical split head defects (see Figure 5), transverse fissures (see Figure 6), and compound fissures. These three types of rail defects are known to originate from manufacturing imperfections (such as voids and inclusions). For example, ingot cast rails manufactured in the 1970s were found to be particularly prone to vertical split head defects. As rail manufacturing processes evolve and improve, the occurrences of transverse fissures, compound fissures, and vertical split head defects are expected to diminish over time.

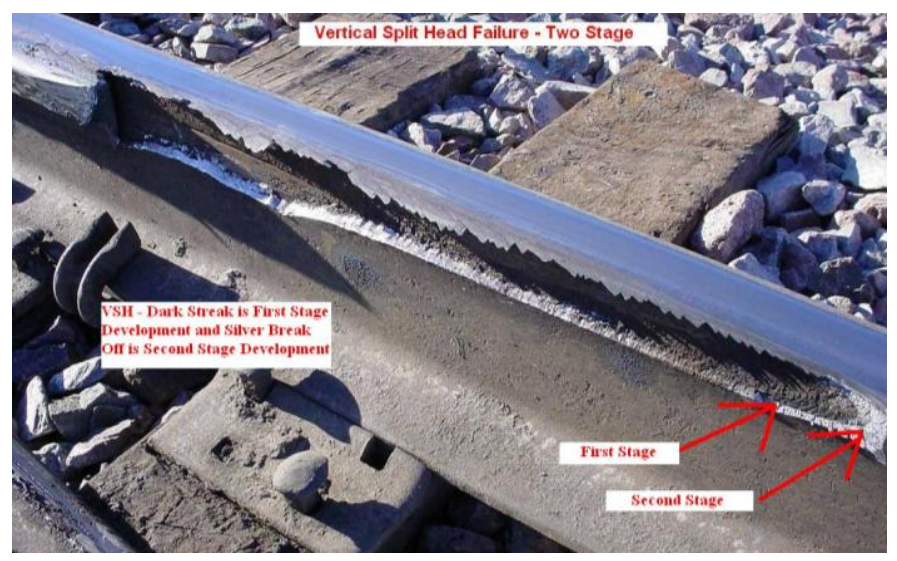

Figure 5: Photograph of Vertical Split Head [2]

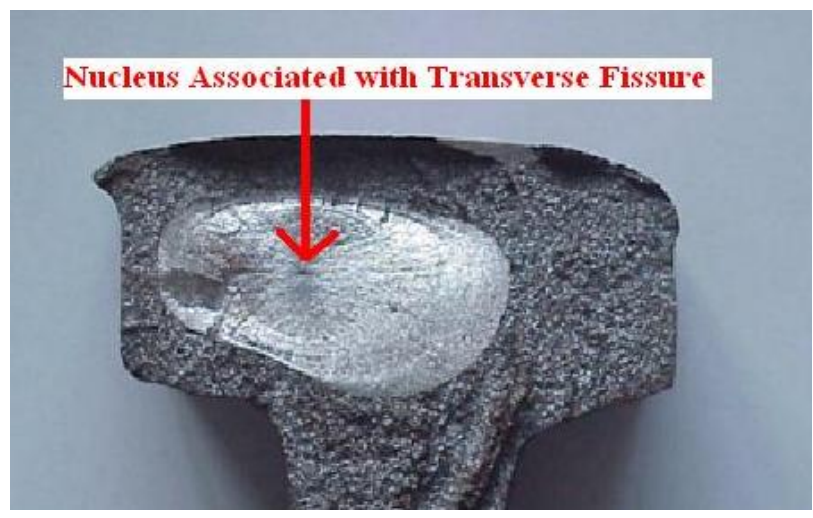

Figure 6: Photograph of Transverse Fissure in Rail [2]

WMATA records indicate that about 44 percent of all broken rails between 2008 and 2010 were due to detail fractures. Over the same time frame, the probable cause of roughly 16 percent of the broken-rail derailments on all freight railroads in the US was the formation and growth of a detail fracture [4]. Between January and March of 2015, over 50 percent of the rail breaks on WMATA were due to detail fractures or compound fissures [5].

Rolling contact fatigue (RCF) damage occurs on the running surface of rails and wheels in nearly all railroad systems, both passenger and freight. The types of surface conditions that are typically characterized as RCF damage are known as shells, flaking, burned rail, head checking, and spalling. Detail fractures often grow from RCF damage. In addition, any type of surface condition can adversely affect the detection of an underlying rail defect. That is, surface damage can inhibit detection of internal rail head defects by impeding the ultrasonic signals into the rail.

Another condition that occurs in all railroads is broken rails originating from defects in the rail base in combination with corrosion. Moreover, rail base corrosion is most likely to occur in tunnels due to marine-like environment. Engineering analyses have been conducted in prior research to examine the fracture behavior of defects in the rail base [6]. 


\section{CONTROL OF RAIL INTEGRITY}

At WMATA, pull-apart events trigger an alarm within the track circuit system that automatically forbids train movement through the block which reduces or eliminates the risk of derailment. However, broken-rail events, especially pull-aparts that occur during the cold temperatures of pre-dawn, cause service disruptions that can adversely affect rush-hour commuting. If the gap created by the pull-apart (due to tensile rail force) is less than three inches, a small maintenance team is dispatched to re-connect the rail with a pair of joint bars, creating a single rail joint. This process takes about one hour. If the gap is greater than three inches, a full crew is needed to replace the broken rail with a 39 -foot section which is connected using two pairs of joints bars, creating two rail joints. In either case, operations and customer satisfaction are significantly and adversely impacted. In addition, high impact loads and stresses are known to occur in jointed rail. Eventually, these "open joints" are replaced with welds at a later time. Consequently, jointed rail and poorly welded joints have become a rail integrity issue at WMATA due to a large backlog of open joints that has built up over time.

Therefore, preventative measures to control rail integrity are of primary importance to WMATA. Three major measures are being implemented: rail inspection using ultrasonic testing, rail grinding, and removal of the open (or temporary) joints. Rail defects and preventative maintenance programs are documented using enterprise application software (EAS) that records pertinent data at the exact location in the rail system. WMATA has been using its EAS system since 2012.

Ultrasonic testing at WMATA is currently conducted inhouse using a general-purpose inspection car, called the Track Geometry Vehicle (TGV). As its name implies, the primary mission of the $\mathrm{TGV}$ is to measure track geometry characteristics (e.g. gauge, rail profile, crosslevel, alignment, warp, etc.), but it is also equipped with ultrasonic sensors to detect internal rail defects at speeds between 5 and $10 \mathrm{mph}$. If a rail defect is detected by the TGV, a track work group that trails the TGV will remove the defect.

In general, ultrasonic testing with the TGV has been effective in finding many types of defects before they can become rail breaks. However, in some cases, especially in areas with heavy surface conditions (such as head checking, spalling, and shelling), the TGV has difficulty detecting transverse defects that are not perpendicular to the sound path. In such cases, the location is labeled as a "Non-Testable Area."

Rail testing is required at least twice a year on WMATA's mainline track. Previous research conducted by the Volpe Center indicates that the occurrence of rail failures can be controlled by adjusting the frequency of rail tests based on the number of detected defects, the number of service failures (i.e. broken rails), and number of previous rail tests over a given time frame [7]. Moreover, this so-called self-adaptive algorithm is applicable to rail systems carrying either or both passenger and freight traffic.
During last several decades, rail grinding has emerged as an important maintenance procedure for all rail systems to manage rail defects and extend rail life [8]. Rail grinding has been used by freight railroads and transit systems to remove rail surface defects such as corrugations, engine burns, flaking, and shelling. These rail surface defects are also referred to as rolling contact fatigue (RCF) damage, which can occur on wheels as well as rails in passenger and freight railroads [9]. An aggressive rail grinding program was introduced at WMATA in 2013 to remove surface defects, especially along curves in the system. Removal of surface damage should improve the likelihood of detecting internal rail defects by ultrasonic testing. Grinding is performed five to six nights per week, averaging 2,000 to 3,500 feet of track per night.

On WMATA, service begins at 5 a.m. on weekdays, 7 a.m. on weekends and closes at midnight Sunday to Thursday, 3 a.m. on Friday and Saturday nights. Therefore, rail testing, rail grinding, and re-welding of jointed rail must be completed within a four- or five-hour time period per day, which is further shortened by the time to stage maintenance-of-way equipment to the location.

\section{ENGINEERING ANALYSES}

Previous research has been conducted to study the growth of detail fractures in rail [10]. This research was sponsored by the Federal Railroad Administration (FRA) and carried out by the Volpe Center. Moreover, the engineering fracture mechanics analyses developed from this previous research can be applied to help understand the occurrences of broken rail. In this paper, rail failures are examined with and without wheel loading, assuming that the internal defect in the rail is a detail fracture.

One of the most significant factors that affect stresses in rail is the rail temperature relative to the stress-free or neutral temperature. Figure 7 is a schematic diagram that shows how various factors in combination with the nature of this temperature differential (i.e. whether the longitudinal rail force is compressive or tensile) determine whether lateral instability of the track (or track buckling) or rail failure (or broken rail) will occur. Extensive research on track buckling has also been conducted and sponsored by the Volpe Center and the FRA [11]. 


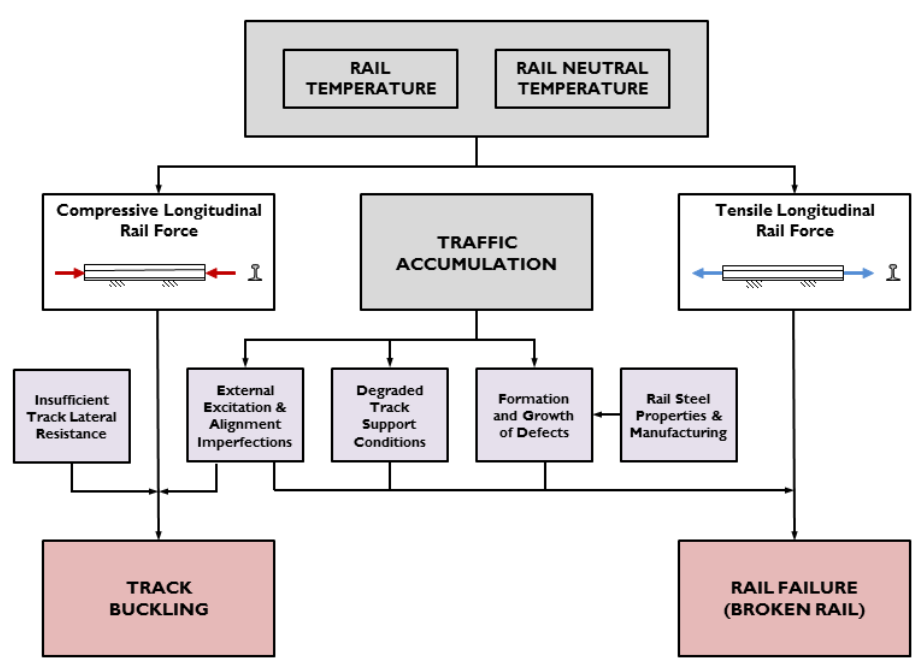

Figure 7: Factors Affecting Track Buckling and Broken Rail

\section{Analysis of Pull-apart Rail Failure}

Broken rail can sometimes occur without the presence of wheel loads. These sudden rail failures are called pull-aparts. In theory, pull-apart rail failures occur when the defect size and the tensile longitudinal stress become large enough to reach a critical state. Referring to Figure 8, the longitudinal or axial stress in rail without wheel load consists of two components: (1) thermal stress due to the difference in rail temperature and the stress-free state, and (2) residual stress.

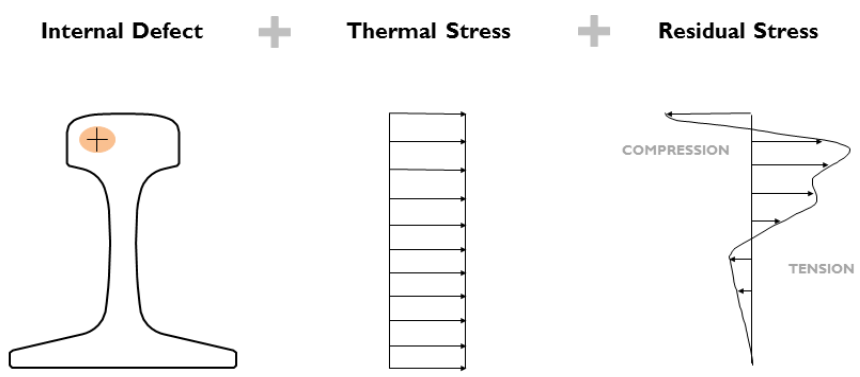

Figure 8: Longitudinal Rail Stresses without Wheel Load

Residual stresses are those that remain in an externally unloaded rail. Residual stresses develop in rail from: (1) heat treatment during manufacturing, (2) roller-straightening during manufacturing, and (3) plastic deformation from in-service rolling contact loading. Residual stresses in rail may also develop from welding and grinding. Moreover, the quantification of residual stresses by either experimental or analytical means has been found to be challenging.

Figure 9 shows the effects of temperature differential and residual stress on the critical defect size. Here "critical" defect size means the size of the internal rail head defect at which rail failure is expected to occur. As rail temperature decreases and as residual stresses become more tensile, the critical defect size becomes smaller; i.e. the rail becomes less damage tolerant.

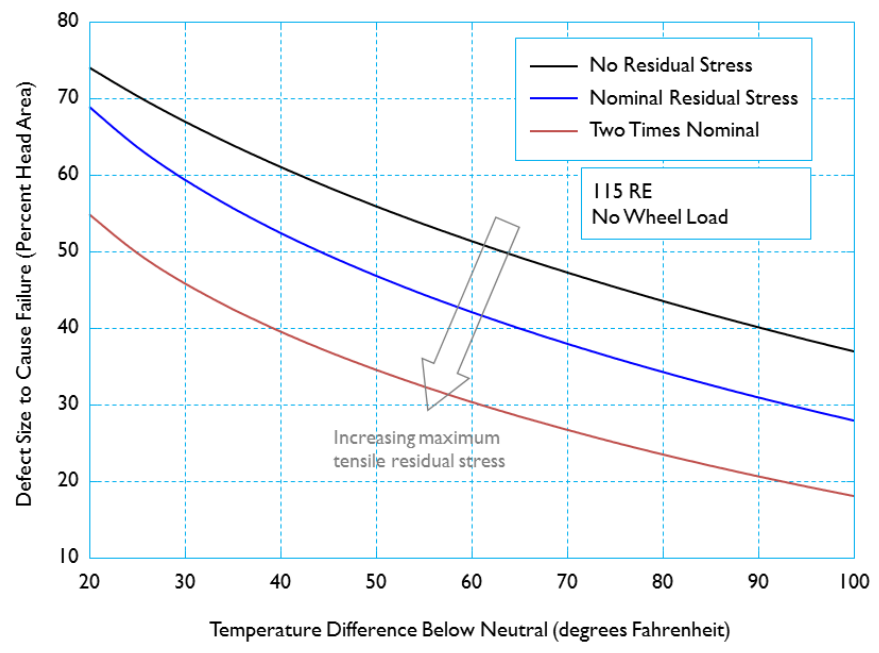

Figure 9: Effect of Temperature Differential and Residual Stress on Critical Defect Size

The effects of temperature differential and fracture toughness on the critical defect size are illustrated in Figure 10. As rail temperature decreases and as fracture toughness decreases, the rail becomes less damage tolerant and smaller defect sizes will lead to rail failure.

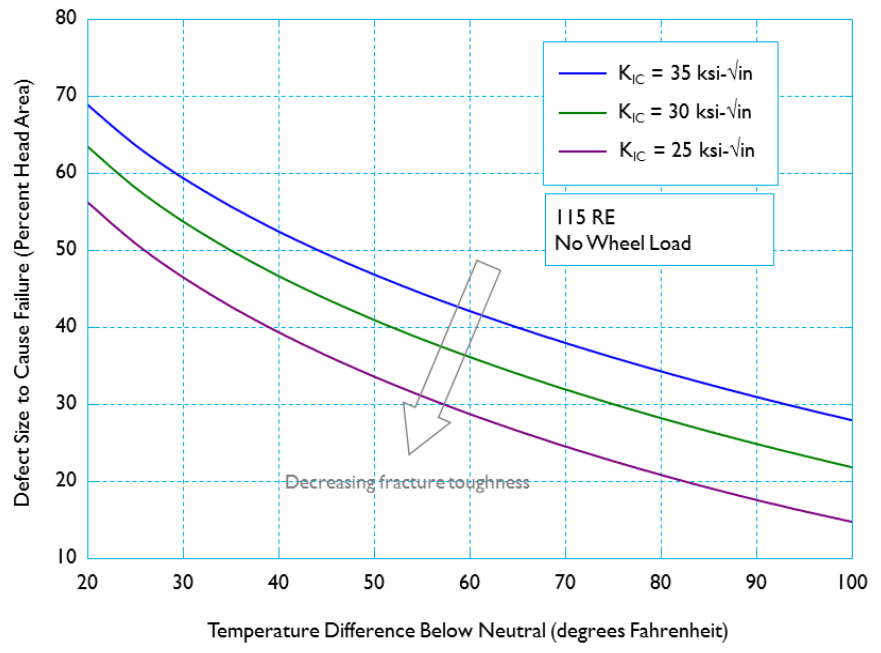

Figure 10: Effect of Temperature Differential and Fracture Toughness on Critical Defect Size

\section{Analysis of Rail Failure under Wheel Loads}

Beam-like bending stresses are created in rail as trains travel over them, which contribute to the total longitudinal stress in the rail (see Figure 11). Rail bending has a vertical and a lateral component. The lateral bending component might be 
significant, especially when a wheel is negotiating over curved track. Bending stresses in the rail head also comprise torsional and head-on-web effects [12], which are included in subsequent analyses.
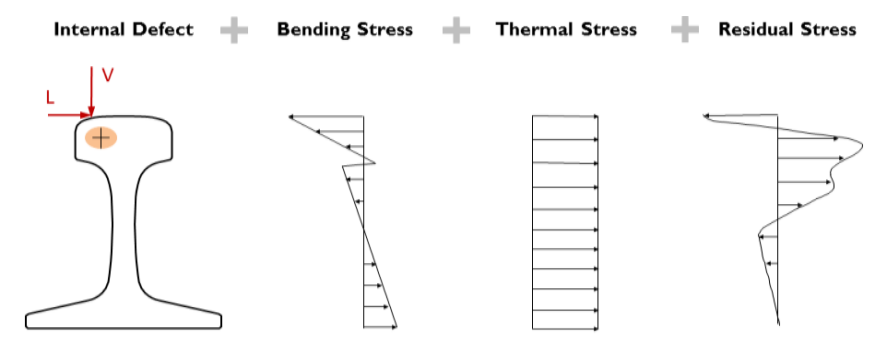

\section{Figure 11: Longitudinal Rail Stresses with Wheel Load}

The magnitude and distribution of the bending stresses depend on the rail section properties, the foundation modulus (i.e. tie-ballast support conditions), and various characteristics of the train make-up. These characteristics include: vehicle weight, number of axles, and the spacing between axles, trucks and couplers. Figure 12 shows the axle spacing, truck center spacing, and coupler-to-coupler spacing assumed for a Metro rail car.

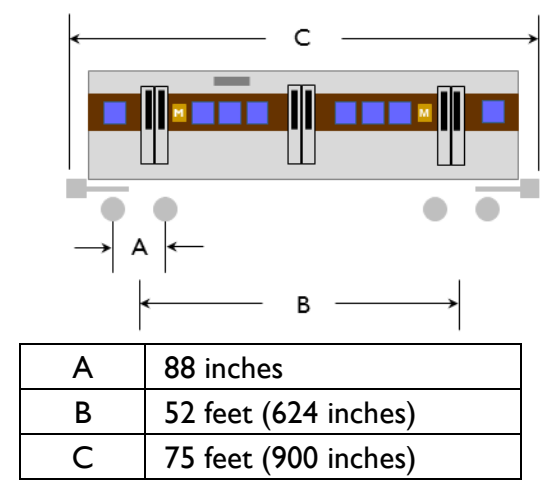

Figure 12: Metro Car Characteristics

Figure 13 shows a schematic of the bending stresses produced by a six-car train. The peaks and valleys in the schematics represent the maximum and minimum bending stresses in terms of cycles for metal fatigue. The locations of the maximum (positive or tensile) stresses occur between wheels. The locations of the minimum (negative or compressive) stresses coincide with locations of the wheels. Case 1 shows the variation of rail stresses along the rail with tensile axial stress superimposed onto the bending stress. Case 2 corresponds to no additional axial stress. Case 3 shows the variation in rail stresses with compressive axial stress superimposed onto the bending stress.

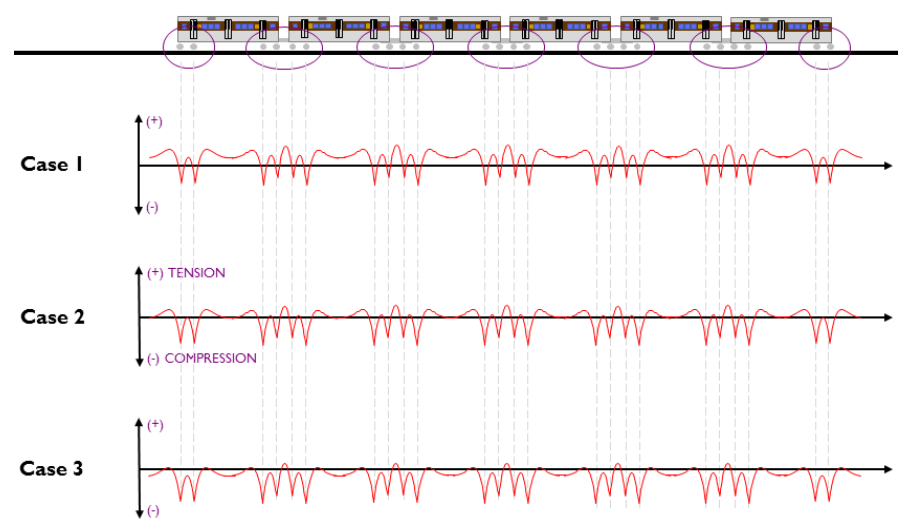

Figure 13: Schematic of Bending Stress Cycles Produced by Six-Car Train

Vehicle weight depends on the number of passengers in the car in addition to the weight of the car. Table 3 lists the average wheel loads estimated for four levels of passenger capacity in a single car. The general description includes the number of passengers assumed for each load level. Each passenger is assumed to weigh $160 \mathrm{lb}$. The maximum wheel load for passenger cars corresponds to AW3 loading level, which has a static load that is slightly less than $15,000 \mathrm{lb}$. For comparison, the maximum wheel load for freight cars is on the order of $36,000 \mathrm{lb}$.

Table 3: Added Weight (AW) Load for Passenger Rail Cars

\begin{tabular}{|l|l|l|}
\hline Level & General Description & $\begin{array}{l}\text { Static } \\
\text { Wheel } \\
\text { Load (lb) }\end{array}$ \\
\hline AW0 & Empty car & 10,000 \\
\hline AW1 & $\begin{array}{l}\text { Car loaded with seated passengers } \\
\text { only (81) }\end{array}$ & 11,620 \\
\hline AW2 & $\begin{array}{l}\text { Car loaded with some seated and some } \\
\text { standing passengers (175) }\end{array}$ & 13,500 \\
\hline AW3 & $\begin{array}{l}\text { Crush load, or the maximum number } \\
\text { of passengers riding in the car, } \\
\text { standing and sitting (232) }\end{array}$ & 14,640 \\
\hline
\end{tabular}

Growth of rail defects (specifically, detail fractures) was calculated based on the stress cycles estimated from beam theory [12]. Figure 14 shows the estimated rate of defect growth for three different passenger load levels. The initial defect size in each curve is 10 percent of the unworn or brand new rail head area, which is assumed to be the smallest detectable size by rail testing equipment. The end points of each curve symbolize the critical defect size, or the defect size 
at which rail failure is expected to occur, for a given load level. The tonnage to grow the defect from barely detectable to the critical size is called the slow crack-growth life. Therefore, the slow crack-growth life is the window of opportunity to detect a rail defect before it becomes large enough to cause rail failure. From Figure 14, the slow crack-growth life for AW1 loading is 86 million gross tons (MGT). For AW2 loading, the slow crack-growth life is $68 \mathrm{MGT}$; for AW3, the growth life is reduced to 60 MGT. The figure also shows that the slow-crack growth life corresponding to the maximum freight wheel load of 36 kips is 37 MGT. Clearly, these results indicate that slow crack-growth life decreases as the average wheel load increases. Moreover, the growth life for passenger loading is much longer than that for freight loading. In these results, no temperature differential is assumed, corresponding to Case 2 in Figure 13. In addition, a vertical foundation modulus of $2,000 \mathrm{psi}$ is assumed, which is representative of average tie-ballast support conditions. This value of foundation modulus is also assumed in the subsequent calculations in the remainder of this paper. The effect of foundation modulus on defect growth is relatively moderate [10].

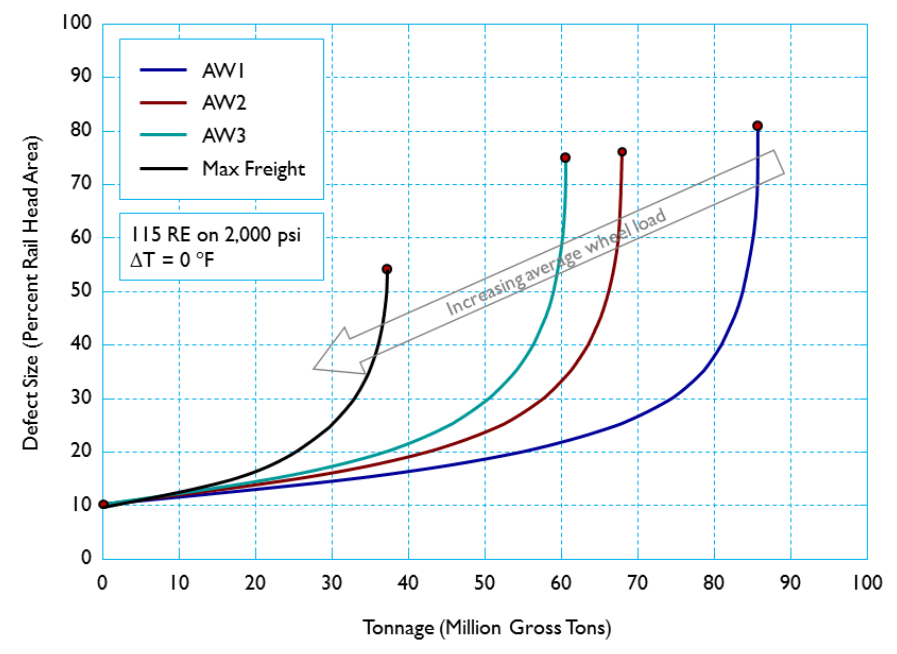

\section{Figure 14: Effect of Wheel Load on Defect Growth}

Figure 15 shows the effect of temperature differential on the defect growth rate for AW2 loading. The slow crack-growth life for rail with no longitudinal force is 68 MGT. The slow crack-growth life is reduced to 48 MGT at a temperature differential of $10^{\circ} \mathrm{F}$, and to $37 \mathrm{MGT}$ at $20^{\circ} \mathrm{F}$. Moreover, the figure clearly shows that the slow crack-growth life decreases and that the rate of defect growth accelerates as the temperature differential increases. As shown previously for pull-aparts (recall Figure 9), the critical defect size decreases with an increase in temperature differential with wheel load.

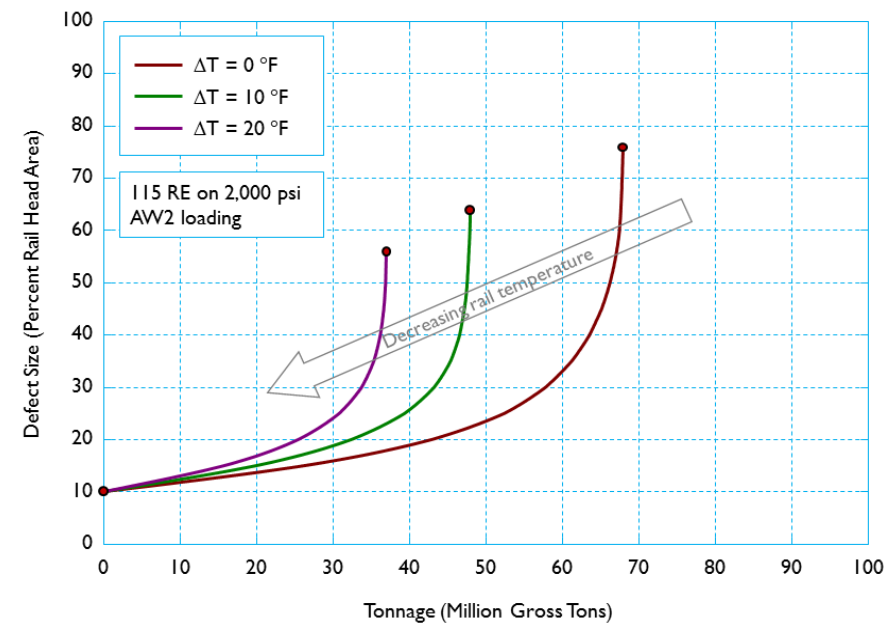

\section{Figure 15: Effect of Temperature Differential on Defect} Growth

Interestingly, Figure 14 and Figure 15 show that the slow crack-growth life for maximum freight wheel loading with no temperature differential (37 MGT) is equal to that for AW2 loading with a temperature differential of $20^{\circ} \mathrm{F}$. Moreover, temperature differential and wheel load have a significant effect on the growth behavior of internal rail head defects.

Figure 16 plots the wheel load to cause rail failure as a function of defect size for three different values of temperature differential. As the defect grows and its size becomes larger, the dynamic wheel load to cause rail failure drops. As shown previously, the wheel load to fracture the rail decreases as the rail temperature decreases, corresponding to greater tensile rail longitudinal force. Foundation modulus has a moderate to weak effect on the wheel load to rail failure.

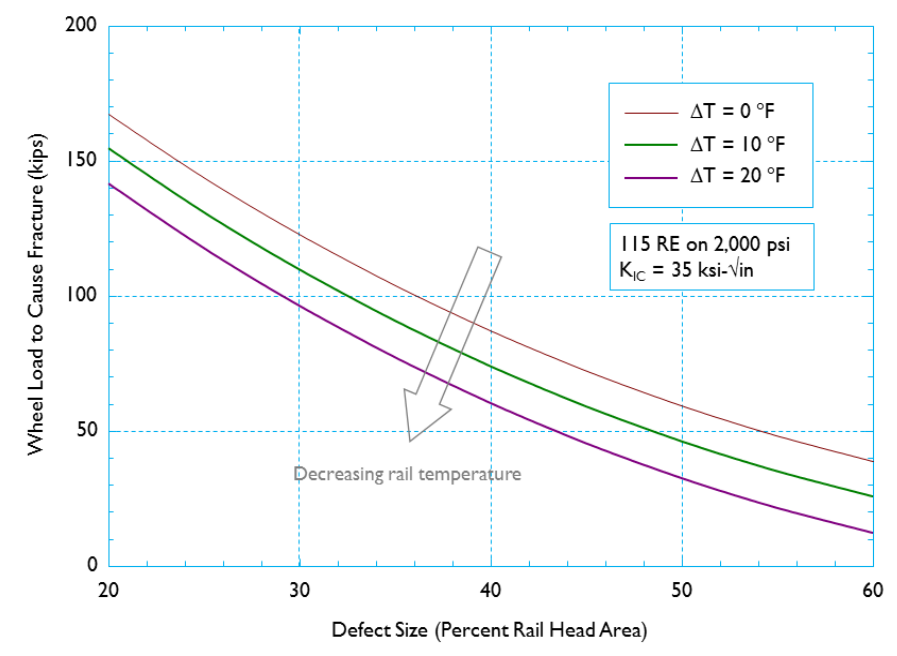

Figure 16: Effect of Temperature Differential on Wheel Load to Fracture and Defect Size 
Fracture toughness of rail steel may vary depending on chemical composition, manufacturing process, and service temperature. Fracture toughness generally decreases as the service temperature decreases and as loading rate increases. That is, rail steel becomes more brittle with colder temperatures and faster loading rates. Referring to Figure 17, the wheel load to cause rail fracture appears to be a linearly decreasing function of temperature differential. The wheel load to cause fracture in a rail containing a defect comprising 20 percent rail head area is $129 \mathrm{kips}$ for a temperature differential of $30^{\circ} \mathrm{F}$ and fracture toughness of $35 \mathrm{ksi}-\sqrt{\mathrm{in}}$. For the lower-bound fracture toughness of $25 \mathrm{ksi}-V_{\mathrm{in}}$, the wheel load to cause rail failure is 67 kips at the same temperature differential. Therefore, fracture toughness appears to have a relatively strong effect on the dynamic wheel load to cause rail failure.

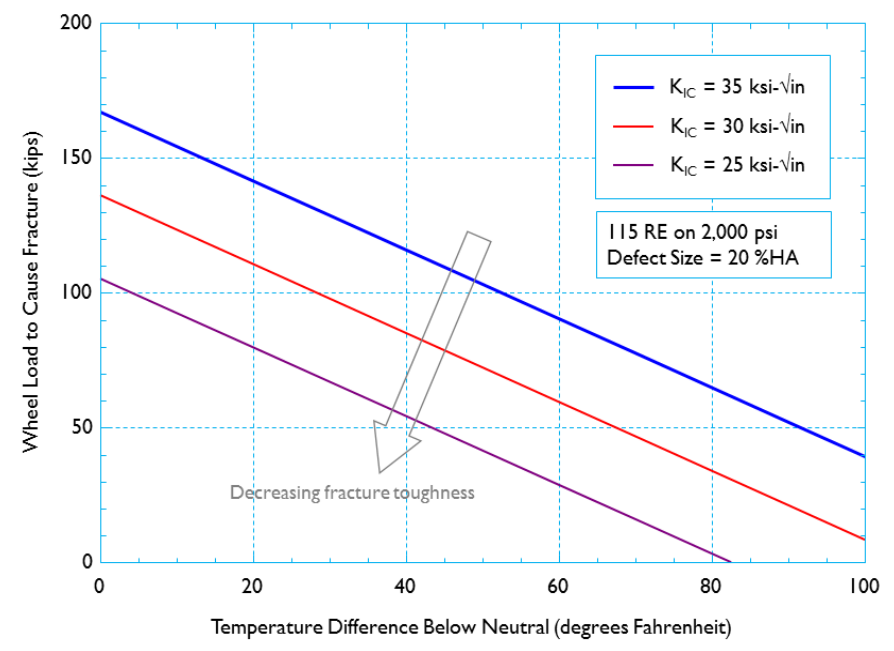

Figure 17: Effect of Fracture Toughness on Wheel Load to
Fracture

The results from engineering fracture mechanics analyses clearly show that temperature differential (i.e. colder temperatures) play a significant role in the fracture behavior of rail. These theoretical results are consistent with the recent WMATA experience with broken rails. Over a three-year period between 2012 and 2014, more than half of the rail breaks on the Metro rail system occurred during the cold-weather months of December, January, and February.

\section{CONCLUDING REMARKS}

This paper describes rail integrity issues that the Washington Metro rail system has been managing, which are similar to those that freight railroads also face. These issues include the development and growth of internal rail head defects that might lead to rail failure or broken rail.

This paper also presents results from engineering analyses, which are intended to help understand the mechanics of broken rail. The three most significant factors affecting critical defect size for pull-apart rail failures are: (1) rail temperature below neutral or stress-free temperature, (2) fracture toughness of the rail steel, and (3) residual stress in the rail. The prerequisites for sudden pull-apart rail failures (i.e. rail without wheel load) are an internal rail defect and one or a combination of the following conditions:

(a) "High" stress-free or neutral temperature,

(b) "Low" fracture toughness of rail steel,

(c) "High" level of tensile residual stress in the rail head.

Engineering fracture mechanics analyses were also performed for rail with applied wheel loads. The results from these analyses demonstrate that as the longitudinal rail force becomes more tensile (e.g. as rail temperature decreases): (1) the growth rate of rail defects accelerates, and (2) the wheel load to cause rail failure reduces. Moreover, broken rails are expected to occur more often in colder weather, which correlates to the actual rail integrity experience on WMATA as well as on freight railroads.

Assuming AW2 loading, the slow crack growth life (or the time for a defect to grow from barely detectable size to the size at which failure is expected to occur) on the part of rail system where the Blue, Orange, and Silver Lines coincide is between three to five years. If ridership increases and the use of 8-car consists becomes more prevalent, the slow crack growth life will become shorter.

The information presented in this paper may be useful to other rail systems, both passenger and freight, that are currently facing similar rail integrity issues.

\section{ACKNOWLEDGMENTS}

The engineering fracture mechanics analyses described in this paper were developed over the course of previous research conducted and managed by the Volpe National Transportation Systems Center, and sponsored by the Federal Railroad Administration.

Technical discussions with Dr. Benjamin Perlman, Senior Engineer at the Volpe Center, particularly his comments and suggestions in writing of this paper, are gratefully appreciated and acknowledged.

\section{REFERENCES}

1. http://www.wmata.com/about metro/?forcedesktop=1

2. Federal Railroad Administration, Office of Railroad Safety, “Track Inspector Rail Defect Reference Manual," Revision 2, July 2015

https://www.fra.dot.gov/Elib/Document/15056

3. http://www.weather.gov/climate/xmacis.php?wfo=lwx

4. Federal Railroad Administration, Railroad Accident and Incident Report System (RAIRS)

http://safetydata.fra.dot.gov/OfficeofSafety/Default.aspx

5. WMATA Track and Structures (TRST) Rail Break Database, Retrieved March 2015.

6. Jeong, D.Y., Carolan, M.E., Yu, H., and Perlman, A.B., "Fracture mechanics and beam theory analyses of semi- 
elliptical cracks originating in the base of rail," Proceedings of the 2012 Joint Rail Conference, JRC201274027, April 2012

http://ntl.bts.gov/lib/44000/44600/44615/Jeong_Fracturem echanicsBeam.pdf

7. Orringer, O., "Control of Rail Integrity by Self-Adaptive Scheduling or Rail Tests," DOT/FRA/ORD-90/05, June 1990

http://ntl.bts.gov/lib/35000/35200/35241/DOT-

VNTSCFRA-90-02.pdf

8. Zarembski, A.M., The Art and Science of Rail Grinding, Simmons-Boardman Books, Inc., Omaha, Nebraska, 2005

9. Tunna, J., "Rolling contact fatigue in passenger and freight railroads," Proceedings of the 2010 Joint Rail Conference, JRC2010-36039, April 2010
10. Orringer, O., Tang, Y.H., Gordon, J.E., Jeong, D.Y., Morris, J.M., and Perlman, A.B., "Crack Propagation Life of Detail Fractures in Rail," DOT/FRA/ORD-88/13, October 1988 http://ntl.bts.gov/lib/34000/34200/34244/DOT-TSC-FRA88-01.pdf

11. Kish, A., Samavedam, G., and Al-Nazer, L., "Track Buckling Prevention: Theory, Safety Concepts, and Applications," DOT/FRA/ORD-13/16, March 2013 https://www.fra.dot.gov/Elib/Document/3036

12. Timoshenko, S., and Langer, B.F., "Stresses in Railroad Track," ASME Transactions 54 (1932), pp. 277-293. 